\title{
OS ATRIBUTOS VALORIZADOS POR CRIANÇAS E ADOLESCENTES NA ESCOLHA DE DESTINOS TURÍSTICOS
}

ATTRIBUTES VALUED BY CHILDREN AND TEENS IN THE CHOICE OF TOURIST DESTINATION

LOS ATRIBUTOS VALORIZADOS POR NIÑOS Y ADOLESCENTES EN LA ELECCIÓN DE DESTINOS TURÍSTICOS

\section{Marta Maria Cunha Carneiro}

Doutoranda em Administração (FEA/USP)

dramarta@outlook.com

Prof. Dr. Andres Rodriguez Veloso

Livre Docente (FEA/USP)

Doutor em Administração (FEA/USP)

veloso@usp.br

\section{Sofia Batista Ferraz}

Doutoranda em Administração (FEA/USP) sofiaferraz@usp.br

Prof. Dr. Marcos Cortez Campomar

Professor Titular (FEA/USP)

Doutor em Administração (FEA/USP)

campomar@usp.br

Data de Submissão: 24/02/2015

Data de Aprovação: 05/06/2015

Resumo: O objetivo do artigo foi identificar os atributos valorizados por crianças e adolescentes na escolha de destinos turísticos. Para atingir esse objetivo, foram coletados desenhos e dados escritos (questões e redações) sobre o tema com crianças de 10 a 11 anos (18 crianças) e adolescentes de 14 anos (10 adolescentes) da mesma escola. Por meio do processo de análise de conteúdo, foram identificadas seis categorias: Motivação para a viagem; Destino; Modalidade de transporte; 
Acompanhantes; Atividades; e Emoções. As categorias foram divididas em subcategorias para facilitar a discussão e a compreensão detalhadas. Apesar das semelhanças por tratar-se de um período de transição, os resultados evidenciam principalmente as distinções entre os atributos valorizados pelas crianças e pelos adolescentes devido aos diferentes estágios cognitivos e sociais em que se encontram. São oferecidas sugestões gerenciais para aqueles interessados em atender às famílias com crianças ou adolescentes com produtos turísticos. Por fim, apresentam-se limitações e sugestões de estudos futuros.

Palavras chave: Crianças. Adolescentes. Destinos turísticos.

\begin{abstract}
The objective of this research was to identify the attributes valued by children and teens when choosing a tourist destination. To achieve this objective, drawings and written data (questions and essays) on the subject were collected, from children aged 10-11 years (18 children) and teenagers aged 14 years (10 teenagers) attending the same school. Using content analysis, we identified six categories of analysis: Motivation for the trip; Destination; Mode of transport; Escorts; Activities; and Emotions. The categories were divided into subcategories to facilitate discussion and a more detailed understanding. Despite the similarities found, given that this is a period of transition, the results mostly highlighted the distinctions between the attributes valued by the children and the adolescents, due to their different cognitive and social stages. Managerial suggestions are offered for those interested in serving families with children or adolescents with tourism products. Finally, we present some limitations and suggestions for future studies.
\end{abstract}

Keywords: Children. Adolescents. Tourist destinations.

Resumen: El objetivo de este artículo fue identificar los atributos valorizados por niños y adolescentes en la elección de destinos turísticos. Para alcanzar ese objetivo se recolectaron dibujos y datos escritos (cuestiones y redacciones) sobre el tema con niños de 10 a 11 años (18 niños) y adolescentes de 14 años (10 adolescentes) de la misma escuela. Por medio del proceso de análisis de contenido se identificaron seis categorías: Motivación para el viaje; Destino; Modalidad de transporte; Acompañantes; Actividades; y Emociones. Las categorías fueron divididas en subcategorías para facilitar la discusión y la comprensión detalladas. A pesar de las semejanzas, por tratarse de un período de transición, los resultados evidencian principalmente las distinciones entre los atributos valorizados por los niños y por los adolescentes debido a los diferentes estadios cognitivos y sociales en los que se encuentran. Se ofrecen sugerencias gerenciales para aquellos interesados en atender a las familias con niños o adolescentes con productos turísticos. Por último, se presentan las limitaciones y sugerencias para estudios futuros.

Palabras clave: Niños. Adolescentes. Destinos turísticos.

INTRODUÇÃO

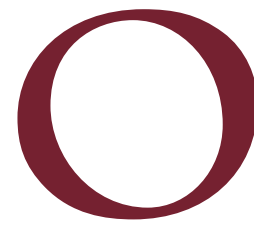
objetivo deste trabalho é identificar os atributos valorizados por crianças e adolescentes na escolha de destinos turísticos.

O Estatuto da Criança e do Adolescente define que crianças têm entre 0 e 12 anos incompletos e adolescentes entre 12 anos completos e 
18 anos de idade. De acordo com a pesquisa de Sondagem do Consumidor de Julho de 2014, cerca de $25 \%$ dos viajantes brasileiros pretendem viajar acompanhados dos filhos (MINISTÉRIO DO TURISMO, 2014). A participação dos filhos no consumo de serviços para uso em família tem sido estudada desde a década de 60 (BEREY; POLLAY, 1968). As viagens são uns dos serviços que mais sofrem influência da criança (JENKINS, 1979).

O estudo da forma como a criança influencia as compras relacionadas ao turismo ainda carece de aprofundamentos (NICKERSON; JUROWSKI, 2001) por ela ter sido desconsiderada e negligenciada durante anos, atribuindo a influência e a decisão somente aos pais (THORNTON et al., 1997). Apesar disso, já se discute a crescente influência da criança nas tomadas de decisão da família, incluindo o destino turístico de feriados e fins de semana (MCNEAL, 1992; GUNTER; FURNHAM, 1998; EVANS; MOUTINHO, 1999; CONNELL, 2005). Os recentes estudos neste campo têm focado sobre a influência (OCKE, 2013; NOVALO, 2012; NOVALO; VELOSO, 2012) no momento do processo decisório (OCKE, 2013), mas não houve maior empenho para compreender qual a motivação da criança nesse esforço de influência, ou seja, quais são os atributos de uma viagem que motivam a criança ou o adolescente a participar do processo decisório.

Para atingir o objetivo proposto, este trabalho está organizado da seguinte forma: primeiramente será apresentado o referencial teórico que fundamenta a compreensão da participação da criança no processo decisório da família, depois será apresentado o método de pesquisa, a análise dos dados e, por fim, as considerações finais.

\section{DECISÃO DE COMPRA DA FAMÍLIA}

A família pode ser compreendida como "conjunto de pessoas, em geral ligadas por laços de parentesco, que vivem sob o mesmo teto, particularmente o pai, a mãe e os filhos" (MICHAELIS, 2014). Famílias compostas por pais e filhos representam 47,3\% dos domicílios, enquanto que mulher com filhos representa 17,4\% (IBGE, 2010). Percebe-se que 64,7\% dos domicílios têm suas compras influenciadas por filhos. A família torna-se então um dos mais importantes centros de compra (VELOSO et al., 2013). 
Pesquisas sobre a tomada de decisão familiar oferecem diversas teorias quanto aos papéis dos indivíduos nos grupos familiares. Inicialmente, a partir de um contexto paternalista e centralizador, assumia-se que o homem (esposo e/ou pai) era o responsável pela tomada de decisão de forma unilateral (FODNESS, 1992). A partir da década de 1950, a mulher foi inserida ao modelo como "agente comprador" (SHARP; MOTT, 1956; THORNTON et al., 1997).

Durante muitos anos, os pais (casal) eram os únicos considerados na tomada de decisão familiar (HEMPEL, 1974; DAVIS, 1976; BURNS; HARRISON, 1982; MANGLEBURG; TECH, 1990). Davis (1976), por outro lado, mostrou que a decisão familiar pode ser dividida em subdecisões que diferem a partir de sua complexidade e natureza. É somente em pesquisas mais recentes que o papel da criança no processo de tomada de decisão é mais debatido (HOWARD et al.,1990).

O papel que a criança assume nas compras familiares é considerado tão importante, que empresas que não atentarem para essa nova força de influência terão dificuldades em atingir a potencialidade total de certos mercados (VECCHIO, 2002). Diversos autores se debruçaram sobre essa temática procurando compreender como se dá a influência da criança nas compras familiares (FOXMAN; TANSUHAJ, 1988; GEUENS et al. 2002; HALL et al., 1995; MANGLEBURG et al., 1999; MCNEAL; YEH, 1997; VELOSO; HILDEBRAND; CAMPOMAR, 2010). De acordo com Vecchio (2002) e McNeal (1999; 2007), essa influência poderá ser direta (a criança solicita) ou indiretamente (os pais pensam na criança ao comprar).

O processo decisório de compra é composto por sete etapas: identificação de necessidade, busca de informações, avaliação das alternativas, compra, consumo, avaliação da satisfação e descarte (ENGEL et al., 2000). Szybillo e Sosanie (1977) identificaram que o processo da tomada de decisões familiares envolve os membros da família (marido, esposa e filhos) nos três estágios de decisão (reconhecimento do problema, busca de informações e seleção final).

A influência das crianças no processo de decisão varia de acordo com a natureza do processo de decisão, a socialização das crianças, a orientação das famílias, o produto, o preço, a idade da criança, etc. (DAVIS, 1976; BELCH et 
al., 1985). Ekstrom et al. (1987) identificaram que a influência da criança pode ocorrer por meio de opiniões e declarações de preferência, por exemplo.

Barry (1980) apresenta um modelo para a determinação da publicidade enganosa ou desleal voltada para o público infantil. McNeal e Ji (1999) realizaram uma pesquisa com crianças chinesas consumidoras para determinar onde elas aprendem informações sobre novos produtos e suas atitudes sobre diferentes fontes de informação. Os pesquisadores concluíram que as crianças chinesas utilizam uma ampla variedade de fontes de informação para aprender sobre novos produtos, incluindo pais, pontos de venda e meios de comunicação. Surpreendentemente eles consideram a televisão como a mais importante de todas. Os efeitos da idade, sexo, família, ocupação também foram considerados. Kaur e Singh (2006), por sua vez, realizaram pesquisas sobre a influência das crianças na decisão de compra da família indiana.

Ekstrom et al. (1987) salientam que em algumas categorias de produto a criança demonstra ter maior conhecimento que seus pais. Quando os pais compreenderem que seu filho possui mais conhecimento sobre o produto que está sendo adquirido pela família, ele irá dar maior liberdade para a criança participar do processo de compra (THOMSON; LAING; MCKEE, 2007). É possível compreender que a influência do filho aumenta com a idade em função do reconhecimento por parte dos pais da capacidade da criança em participar do processo decisório parte em função do aumento do conhecimento sobre diversos produtos. Dessa forma, é natural que, com o avanço da idade, cresça a influência da criança na compra de diversos produtos: serviços para momentos de lazer (DARLEY; LIM, 1986); roupas, salgadinhos e refrigerantes (MEHROTRA; TORGES, 1977).

Para adolescentes, o aumento da participação nas decisões de consumo pode ser relacionado com o aumento do nível de conhecimento do mercado, desaparecimento de fatores que restringiam sua capacidade de comprar (p.ex.: habilidade para dirigir) ou aumento da liberdade cedida pelos pais (MOSCHIS; MITCHELL, 1986). 


\section{COMPRA DE PRODUTOS TURÍSTICOS}

A influência das crianças ocorre em diversas categorias de produtos, como, por exemplo, doces (AHUJA; STINSON, 1993), brinquedos (BURNS; HARRISON, 1982; JENSEN, 1995; WILLIAMS; VEECK, 1998); roupa infantil (CONVERSE; CRAWFORD, 1949; FOXMAN; TANSUHAJ, 1988; HOLDERT; ANTONIDES, 1997); e cereais (BELCH et al., 1985; BEREY; POLLAY, 1968); filmes (DARLEY; LIM, 1986); comer em restaurantes (FILIATRAULT; RITCHIE, 1980; WILLIAMS; VEECK, 1998), atividades nas férias/feriados (AHUJA; STINSON, 1993; BELCH et al., 1985; DUNNE, 1999; HOLDERT; ANTONIDES, 1997; JENKINS, 1979). Nesse último tipo de produto, vários autores concordaram que as crianças têm um papel importante na decisão de compra de férias (NICKERSON; JUROWSKI, 2001; BLICHFELDT et al., 2010; FOXMAN et al., 1989).

A compra de produtos viagens de férias familiares tem aumentado, pois famílias em que ambos os pais trabalham possuem mais recursos financeiros e menos tempo para passar com os filhos e utilizam as viagens de férias como forma de reconectar-se com a família (NICKERSON; JUROWSKI, 2001).

São diversas as pesquisas que apontam para a participação dos filhos nas decisões relacionadas às férias. Por exemplo, Szybillo e Sosanie (1977) verificaram que metade das compras de viagem de família é realizada de forma conjunta, ou seja, com a participação dos pais e dos filhos. Já Foxman et al. (1989) informaram que $60 \%$ das famílias afirmam que adolescentes estão influenciando a decisão sobre férias. O crescimento da importância das viagens de férias para a família com o crescimento da participação da criança no processo decisório potencializa a participação dos filhos nessas decisões. Thornton et al. (1997), por sua vez, avaliaram a influência das crianças no comportamento do grupo em viagens de feriado.

Blichfeldt et al. (2010) baseiam-se nas demonstrações de vários autores (GRAM, 2005; THORNTON et al., 1997) para afirmar que as necessidades e os desejos diferem entre os membros da família. Essas diferenças em relação às necessidades e aos desejos fazem com que em alguns casos as crianças possam ter opiniões diferentes das dos pais em relação à satisfação com atributos das viagens e das visitas a pontos turísticos (NICKERSON; JUROWSKI, 2001). 
ISSN: 1983-7151

Percebe-se, assim, que é importante compreender o que motiva a criança ou o adolescente a frequentar determinado lugar para aumentar as chances de o destino turístico satisfazer todos os membros da família. Essa diferença de necessidades e desejos faz com que seja necessário um processo de negociação familiar para decidir onde e como as férias serão aproveitadas, abrindo espaço para o surgimento de conflitos.

No contexto da resolução de conflitos, Filiatrault e Ritchie (1980) identificaram que as crianças exercem influência em diferentes níveis no decorrer do processo decisório da família, porém elas podem criar coalizões com um dos adultos e assim produzir uma posição majoritária. Holdert e Antonides (1997) relataram que a influência das crianças foi maior nas fases posteriores do processo decisório e que o crescimento da importância no processo decisório familiar ocorre à custa da mãe. Desta forma é possível imaginar que, dependendo do adulto que fizer parte da coalização, a força obtida no processo decisório pode variar.

Apesar de as crianças serem identificadas como influenciadoras do processo decisório de viagens de férias e serem consideradas um mercado consumidor importante (HALAN, 2002; SINGH, 1998), são poucas as pesquisas que focam na opinião dos adolescentes, muito menos das crianças em relação aos seus destinos turísticos preferidos (NICKERSON; JUROWSKI, 2001). Talvez isso ocorra porque as crianças não são o público-alvo da indústria turística e, na maioria dos casos, assume-se que elas vão se submeter às escolhas dos pais e que possuem pouca influência na escolha de um destino em especial (CULLINGFORD, 1994).

De acordo com Thornton et al. (1997), dois fatores indicam o contrário: primeiro, a satisfação da criança é extremamente considerada pelos pais e, se ela não deseja ir a determinado lugar, a decisão e a satisfação quanto à própria viagem pode ser comprometida; em segundo, o público infantil é um dos mais exigentes e está menos preparado para experiências ruins (RYAN, 1992). A valorização da criança no núcleo familiar explica essa questão (MONTIGNEAUX, 2003), principalmente porque a partir do século XX a criança passa a ser vista como algo sagrado e insubstituível (SCHOR, 2004). A criança, portanto, possui um papel significativo na tomada de decisão e pode exercer influência (SEATON; TAGG, 1995), mesmo que isso ainda não tenha sido amplamente reconhecido. 
Em geral as pesquisas são realizadas com os pais como respondentes, fazendo com que as informações sobre a criança venham de outras fontes (BLICHFELDT et al., 2010). Mesmo que os pais possuam um alto conhecimento sobre a criança, é possível imaginar que essa informação pode ser incompleta e enviesada. Desta forma este trabalho procura compreender o que pensa a criança quando se fala de viagens e de turismo.

\section{PROCEDIMENTOS METODOLÓGICOS}

O objetivo do estudo é analisar os atributos valorizados pelas crianças e pelos adolescentes na escolha de destinos turísticos. Para este trabalho, optou-se por utilizar uma linha de pesquisa qualitativa, descrita por Campomar (1991, p. 96) da seguinte forma: "[...] nos métodos qualitativos não há medidas, as possíveis inferências não são estatísticas e procura-se fazer análises em profundidade, obtendo-se até as percepções dos elementos pesquisados sobre eventos de interesse". Trata-se, ainda, de um estudo descritivo, por buscar documentar quais crenças, atitudes, códigos, estruturas e processos ocorrem neste fenômeno (MARSHALL; ROSSMAN, 1995). Flick (2009) afirma que a pesquisa qualitativa caracteriza-se por um embasamento teórico, por conceitos da realidade e por uma metodologia própria.

No campo da ciência da Administração, pode-se fomentar como técnica de análise de dados a análise de conteúdo que, nos últimos anos, tem ganhado legitimidade entre os métodos qualitativos. A análise de conteúdo proporciona rigor científico e profundidade das pesquisas. É uma técnica que exige muita dedicação e tempo do pesquisador, além de intuição e criatividade na categorização da análise (MOZZATO; GRZYBOVSKI, 2011). Chizzotti (1991) acredita que o objetivo da análise de conteúdo é abarcar o sentido das comunicações de forma crítica, seu conteúdo e as significações implícitas ou explícitas.

Apesar do número crescente de pesquisas que utilizam crianças como objeto de estudo, percebe-se a utilização de abordagens metodológicas inadequadas para conhecer a criança como consumidora e influenciadora. A inclusão da perspectiva da criança requer a adoção de técnicas apropriadas que consigam engajá-las no processo de pesquisa (THOMSON et al., 2007). As crianças usam 
desenhos para expressar seu conhecimento sobre o mundo ao seu redor e retratar temas e ideias baseadas nas próprias experiências e nas experiências indiretas por meio da mídia e dos meios eletrônicos (GAMRADT, 1995).

Optou-se por um estudo com 28 crianças de duas classes de uma escola urbana de classe média baixa, localizada no bairro do Bosque dos Eucaliptos, próxima ao aeroporto de São José dos Campos, no Estado de São Paulo. O valor da mensalidade em 2012 era de $R \$ 574,94$ reais, correspondente a 92,43\% do salário mínimo vigente no período. A escola possui ensino fundamental ( $6^{\circ}$ ao $9^{\circ}$ ano) e ensino médio técnico (Administração, Turismo e Informática). A coleta de dados foi realizada no segundo semestre de 2012. A análise dos dados foi iniciada no segundo semestre de 2013 e finalizada em 2014. A pesquisa abrangeu 18 crianças entre 10 e 11 anos e 10 crianças de 14 anos, sendo 14 meninas e 14 meninos. Esta amostra foi selecionada devido à diferenciação dos estágios de socialização de consumo das crianças: analítico (7 - 11 anos) e refletivo (11 - 16 anos). No estágio analítico, as crianças percebem uma complexidade quanto à estrutura de duas ou mais dimensões, já entendem a sua perspectiva e a do outro (antes disso, dos três aos sete anos, só percebem a sua própria), possuem um repertório expandido de estratégias na tomada de decisão e possuem uma adaptabilidade moderada. No refletivo, por sua vez, há uma orientação mais estratégica, na qual percebem uma complexidade multidimensional, entendem a sua perspectiva e a do outro em um contexto social, possuem um repertório completo de estratégias relativas à tomada de decisão e, ainda, possuem uma adaptabilidade já integralmente desenvolvida (JOHN, 1999).

Para cada uma das classes foi desenhado um processo de coleta de dados mais adequado para o seu momento de desenvolvimento, como demonstra o Quadro 1.

Quadro 1 - Processo de coleta de dados

\begin{tabular}{|l|l|l|}
\hline $\begin{array}{l}\text { Método de } \\
\text { coleta de dados }\end{array}$ & Classe 1-10 e 11 anos & Classe 2 - 14 anos \\
\hline Dados escritos & $\begin{array}{l}\text { Onde você gostaria de passar } \\
\text { as férias?"; "Quem ou o que } \\
\text { influenciou a sua escolha?"; e } \\
\text { "O que você vai fazer lá?". }\end{array}$ & $\begin{array}{l}\text { Por favor faça uma redação sobre o local em que } \\
\text { gostaria de passar as férias, indicando quem ou o } \\
\text { que influenciou essa escolha e o que você pretende } \\
\text { fazer nessa viagem. }\end{array}$ \\
\hline Desenhos & $\begin{array}{l}\text { Faça um desenho descrevendo } \\
\text { um dia no local da viagem. }\end{array}$ & $\begin{array}{l}\text { Faça um desenho descrevendo um dia no local da } \\
\text { viagem. }\end{array}$ \\
\hline
\end{tabular}

Fonte: Elaborado pelos autores. 
Com o intuito de deixar as crianças mais à vontade e familiarizadas com a atividade, a pesquisa foi aplicada pela professora que acompanhou, durante uma hora, as respostas das crianças para as perguntas da pesquisa. Os alunos foram convidados a escrever informações sobre os seus perfis: nome, idade, escola, serie e gênero. Apesar de essa estratégia ter tornado o processo de coleta de dados mais familiar para as crianças, também fez com que o pesquisador não tivesse completo acesso à forma como os dados foram coletados. Veloso et al. (2013) explicam que quando o acompanhamento não ocorre de forma próxima, é possível que as crianças copiem as ideias umas das outras.

De acordo com Krippendorff (2013, p.10), a análise de conteúdo relacionase com uma sistemática leitura de um conjunto de matérias, que podem ser textos, imagens ou outras matérias simbólicas. A análise desse material pode ser objetiva ou subjetiva (BARDIN, 2012). Essa característica decorre da relação do pesquisador com o material coletado, pois em alguns casos não existirá uma única leitura do que está sendo analisado. No caso deste trabalho, o resultado final da coleta de dados trouxe 28 desenhos e 28 unidades de material escrito. Esse material compôs a base de dados que foi analisada. É válido ressaltar que, por tratar-se de uma pesquisa exploratória, não se pretende esgotar a discussão ou generalizar os achados para toda a população.

De acordo com Stempel (1989) e Smith (2000), os principais passos do processo de análise de conteúdo são coleta do material, desenvolvimento, teste e aplicação de estrutura de codificação e análise dos dados codificados. O processo de pré-análise começou a partir de uma visão geral do material coletado. Os desenhos foram observados e o material escrito, lido. Após análise preliminar da base de dados, procedeu-se com a criação de categorias que pudessem ajudar no processo de codificação, ou seja, elaborou-se a estrutura de codificação conforme sugerida por Stempel (1989) e Smith (2000). Para agrupamento e análise dos dados, foram utilizadas ainda planilhas do Software Microsoft Excel versão Office 2013. Os conceitos de Bardin (2012) apoiaram o embasamento teórico para a análise. 


\section{ANÁLISE DOS RESULTADOS}

A partir da estrutura de codificação, todo o material foi analisado. Foram definidas seis categorias: Motivação para a viagem; Destino; Modalidade de transporte; Acompanhantes; Atividades; e Emoções.

\section{MOTIVAÇÃO PARA A VIAGEM}

Dentre as motivações para viagem tanto as crianças como os adolescentes sofrem influências das famílias e dos amigos (pares), da mídia. Essas influências podem ser explicadas pela importância dos agentes de socialização (pais, amigos, escola e mídia) no desenvolvimento da criança (MOSCHIS; CHURCHILL, 1978).

Algumas crianças e adolescentes informaram que na escolha do destino não sofreram nenhum tipo de influência, porém ao se analisar o discurso escrito deles percebe-se que existe alguma influência. O exemplo mais claro é de um adolescente que escreveu "na minha decisão ninguém me influenciou, o que realmente me influenciou foi ao ver quão esbeltas são aquelas ilhas". Nesse discurso identifica-se que o adolescente não quer ser visto como influenciável pelos outros, ele tenta afirmar sua condição de pessoa que já possui capacidade para pensar e analisar que aquela é uma boa opção de viagem. Uma delas afirmou que sofre influência do "subconsciente" no momento de escolha.

Percebe-se, ainda neste grupo, a utilização de estratégias de barganha e comprometimento entre pais e filhos ("minha mãe levaria caso tirasse boas notas", "pais prometem levar no aniversário de 15 anos"). No lugar de simples pedidos por produtos, os quais os pais tendem a aceitar ou rejeitar, há uma maior discussão entre as partes devido ao desenvolvimento da habilidade da criança em ver uma situação por diversos pontos de vista (no caso, o dela e dos pais), simultaneamente (RUST, 1993). John (1999) informa que esse comportamento é característico de crianças em estágio analítico de socialização do consumo (entre 7 e 11 anos). Além disso, esse comportamento por parte dos pais funciona como forma de incentivo para obter um empenho maior da criança nas suas atividades de estudo. Essa estratégia pode ser compreendida 
como um processo de modelagem do comportamento via estratégia de reforço positivo (ENGEL et al., 2000).

O grupo de crianças entre 10 e 11 anos ainda viaja acompanhado, predominantemente, dos pais, enquanto as crianças de 14 anos já demonstram a vontade de viajar apenas com os amigos: "iria com minha irmã e alguns amigos, pois não pode ter os pais porque senão eles não iam fazer nada", "ia ser mais legal se meus amigos fossem comigo", "minhas férias seriam magníficas ao lado deles". Nota-se, a partir desse discurso, a importância dos pares como fontes de socialização, que tendem a aumentar sua participação à medida que a criança se desenvolve, em detrimento da influência parental (MOSCHIS; CHURCHILL, 1978).

O grupo de adolescentes de 14 anos relatou em alguns casos a viagem com os pais e em grande parte com os amigos "ia ser mais legal se meus amigos fossem comigo [...] minhas férias seriam magníficas ao lado deles". Outros adolescentes reconhecem que os pais não têm recursos para realizar a viagem. A ausência de recursos pode ser temporal, oriunda das atividades profissionais dos pais, ou financeira. No primeiro caso o adolescente apresenta uma clara compreensão dessas circunstâncias ao afirmar que "Ele trabalha demais e quase não tem tempo para mim, só para negócios e reuniões". No caso da falta de recursos financeiros, outro adolescente diz que "(...) tenho discernimento, sei que meu pai não tem dinheiro (...) agora só tenho algumas coisas a fazer, esperar, trabalhar, sonhar e pedir". Tal fato pode ser atribuído ao desenvolvimento de crianças a pensamentos com padrões adultos, capazes de pensamentos complexos acerca de situações e objetos concretos e hipotéticos (JOHN, 1999).

A influência da mídia é percebida pelo grupo mais novo, apesar de este não relatar um viés persuasivo nos meios ao qual tem acesso (apenas um teor informativo). A criança afirma que "viu na TV, revistas" e "viu na internet", mas não demonstra maior entendimento sobre táticas da propaganda, tipos de vieses ou contextos sociais. A partir das considerações elaboradas foi construído o Quadro 2, onde se resumem os principais achados deste tópico. 


\begin{tabular}{|c|c|c|c|}
\hline Categoria & $\begin{array}{l}\text { Sub } \\
\text { categoria }\end{array}$ & 10 a 11 anos & 14 anos \\
\hline \multirow{4}{*}{$\begin{array}{l}\text { Motivação } \\
\text { para a } \\
\text { viagem }\end{array}$} & $\begin{array}{l}\text { Família e } \\
\text { amigos }\end{array}$ & $\begin{array}{l}\text { A criança viaja acompanhando os pais } \\
\text { ou está na expectativa de viajar em } \\
\text { função de boas notas ou aniversário de } \\
15 \text { anos. Também é comum a viagem } \\
\text { para ver ou rever parentes. }\end{array}$ & $\begin{array}{l}\text { O adolescente ainda planeja viajar com } \\
\text { os pais, mas prepondera a vontade } \\
\text { de viajar com os amigos. Também } \\
\text { aparecem mudanças de planos, como } \\
\text { falta de tempo dos pais ou falta de } \\
\text { recursos. }\end{array}$ \\
\hline & Mídia & $\begin{array}{l}\text { Algumas poucas crianças relatam ter } \\
\text { visto o local preferido na Internet, } \\
\text { revistas e televisão. }\end{array}$ & $\begin{array}{l}\text { Poucos adolescentes reportam utilizar } \\
\text { a mídia como fonte de informações, } \\
\text { porém para alguns poucos é comum } \\
\text { a busca ativa de informações sobre o } \\
\text { destino. }\end{array}$ \\
\hline & Outros & $\begin{array}{l}\text { A criança deseja viajar por conta de } \\
\text { grupos de referência (celebridades, } \\
\text { cantores e atores), preferência } \\
\text { esportiva ou pessoas que lhe } \\
\text { aconselharam. }\end{array}$ & $\begin{array}{l}\text { O adolescente se sente incentivado } \\
\text { a voltar a lugares que já esteve. } \\
\text { Comentários de turistas que já foram lá } \\
\text { também são relevantes. }\end{array}$ \\
\hline & $\begin{array}{l}\text { Não } \\
\text { sofrem } \\
\text { influência }\end{array}$ & $\begin{array}{l}\text { A criança relata não sofrer influência, } \\
\text { porém logo depois indica que houve } \\
\text { influência de grupos familiares. }\end{array}$ & $\begin{array}{l}\text { O adolescente relata que ninguém } \\
\text { Ihe influencia, apenas suas vontades } \\
\text { pessoais e a beleza dos locais que ele } \\
\text { pensa em visitar. }\end{array}$ \\
\hline
\end{tabular}

Fonte: Elaborado pelos autores.

A partir da análise comparativa entre crianças e adolescentes, identifica-se que existe uma tendência já identificável de migrar da vontade de estar com os pais para a vontade de estar com os amigos. Além disso, a compreensão do adolescente das circunstâncias econômicas que cercam uma viagem turística já começa a se tornar mais sofisticada.

\section{MODALIDADE DE TRANSPORTE}

Foram poucas as menções das crianças e dos adolescentes para o processo de ida ao local turístico. Como os estímulos utilizados para coletar dados focaram mais onde as crianças e os adolescentes gostariam de ir e no que fariam lá, isso acabou desviando a atenção dos respondentes. O sonho e a fantasia de viajar de avião é descrito pela criança de 10 a 11 anos na sentença "Prometeu me levar de avião" e pelos adolescentes no momento em que viajam com a 
família. Percebe-se que a viagem de avião, para essa criança em particular, ainda representa parte importante e emocionante da viagem.

Um adolescente cita uma viagem de trem no Canadá, demonstrando já uma compreensão mais aprofundada das opções de transporte que existem em outros países. A compreensão dos adolescentes com relação às possibilidades de viagem aparenta ser mais elaborada que das crianças, o que é natural de acontecer.

Para obter maiores informações sobre as opiniões das crianças e dos adolescentes seria necessário ter desenvolvido estímulos ou questões especificas para esse assunto.

\section{ACOMPANHANTES}

As crianças e os adolescentes retrataram e escreveram sobre as diferentes pessoas que estariam presentes na viagem. As pessoas citadas pelas crianças como acompanhantes de viagem foram, predominantemente, a família e os amigos. Destaca-se nesse caso que as crianças em geral iriam encontrar amigos no local da viagem, em vez de ir viajar com os amigos. Em alguns casos o objetivo principal da criança parece ser encontrar esses amigos que moram no lugar para o qual elas pretendem viajar.

Com relação aos adolescentes, a família ainda é importante, porém começa a se notar uma importância cada vez maior para os amigos. Esses amigos deixam de ser uma pessoa que será visitada no local da viagem, para ser um companheiro que irá viajar junto para algum outro lugar, conforme pode ser visualizado no Quadro 3. 
Quadro 3 - Resumo da categoria Acompanhantes

\begin{tabular}{|c|c|l|l|}
\hline $\begin{array}{c}\text { Catego } \\
\text { ria }\end{array}$ & $\begin{array}{c}\text { Subcate- } \\
\text { goria }\end{array}$ & \multicolumn{1}{|c|}{10 a 11 anos } & \multicolumn{1}{c|}{14 anos } \\
\hline Família & $\begin{array}{l}\text { Diversos familiares são citados como } \\
\text { acompanhantes da viagem, como, por } \\
\text { exemplo, pais, avós, primos, tios, padrinhos. }\end{array}$ & $\begin{array}{l}\text { Os familiares citados diminuem } \\
\text { em número, focando } \\
\text { principalmente nos pais. }\end{array}$ \\
\cline { 2 - 4 } nhantes & Amigos & $\begin{array}{l}\text { Muitos amigos são citados como possíveis } \\
\text { pessoas que serão encontradas no destino, } \\
\text { porém geralmente não fazem parte do grupo } \\
\text { que irá viajar. }\end{array}$ & $\begin{array}{l}\text { Os amigos começam a se tornar } \\
\text { importantes como um potencial } \\
\text { parceiro para acompanhar na } \\
\text { viagem desde seu começo, não } \\
\text { só nos locais turísticos. }\end{array}$ \\
\hline
\end{tabular}

Fonte: Elaborado pelos autores.

Percebe-se, mais uma vez, o amadurecimento da criança nessa transição para a adolescência. Nesse processo os grupos que são importantes mudam, fazendo com que o peso dos agentes de socialização (pais, amigos, escola e mídia) mude. O adolescente passa a valorizar aqueles agentes que envolvem seus amigos e colegas da mesma faixa etária.

\section{DESTINO}

O primeiro item identificado ao analisar os dados coletados é que as crianças possuem uma predileção maior que a dos adolescentes para visitar casas de parentes. As crianças indicam que querem ir para a casa de madrinhas, tios, avós, enquanto que apenas um adolescente colocou que gostaria de ir para a casa do pai, mas por razões ligadas à separação dos pais e pela ausência do pai.

As crianças também têm uma preferência mais destacada que os adolescentes para ir para hotéis, desde que eles sejam chiques e com infraestrutura para sua diversão (p.ex.: piscina, chalé). Uma das crianças citou que preferia ir para um resort. Já no caso dos adolescentes, apenas um deles citou um hotel, mas destacou que ele deveria ficar de frente para a praia.

O clube foi citado por apenas uma criança, desejando ir nesse local para aproveitar a piscina. Percebe-se que existe uma tendência das crianças em estar em locais onde existam piscinas, praias ou outras possibilidades de contato com a água. 
Com relação à cultura do lugar a ser visitado, apenas adolescentes reportaram isso como sendo um atrativo para justificar a ida a determinado local turístico. Esses adolescentes colocaram que teriam interesse em conhecer locais onde poderiam entrar em contato com novas culturas, conhecer os hábitos dos locais, ver como se vestem, experimentar sua culinária e treinar outra língua.

Algumas crianças citaram que gostariam de viajar para acompanhar um jogo de futebol do Sport Club Corinthians Paulista. Os adolescentes não mencionaram esse tema como explicação para o destino escolhido.

Outro tópico que foi altamente presente nas considerações das crianças foi a natureza. Diversas crianças escreveram e desenharam que gostariam de entrar em contato com a natureza, seja ao frequentar praias bonitas, nadar, passear no parque e ir ao zoológico. Já os adolescentes não citam diretamente a natureza, porém diversas cidades que eles pretendem visitar estão localizadas no litoral ou em regiões de praia.

Ao analisar o destino colocado pelas crianças e pelos adolescentes, verificouse que em ambos os grupos existe uma compreensão de que as possibilidades de viagem não se restringem ao seu estado ou país. Metade dos respondentes escolheu o Brasil como destino turístico e a outra metade escolheu países estrangeiros: em particular América do Norte (Estados Unidos, Canadá) ou lugares exóticos (ex.: Caribe, Havaí, Japão), conforme exemplificado na Figura 1.

Ao analisar a Figura 1, percebe-se que a criança valorizou a presença da família na viagem. Além disso, a criança representou alguns locais turísticos do país, como o Monte Fuji e a Tokyo Tower. Identificou-se na pesquisa que cerca da metade dos respondentes pensa em ir para lugares conhecidos e a outra metade prefere ir para lugares novos. A criança que quer ir para o Japão já esteve lá, explicando assim seu conhecimento sobre o local e a vontade de rever pontos turísticos onde já esteve. 
Figura 1: Desenho sobre destino de viagem (exterior)

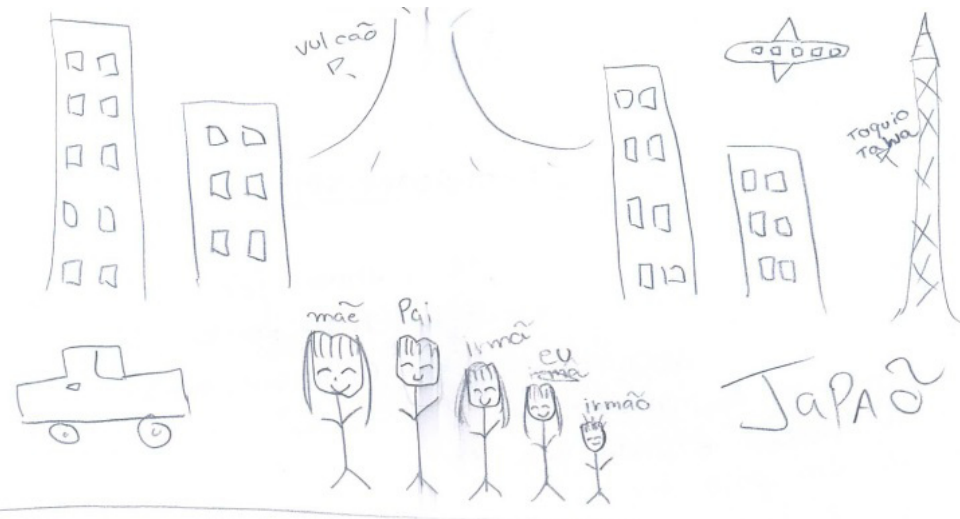

Fonte: Coleta de dados.

Ao analisar comparativamente os dois grupos, notou-se que a vontade de ir ao exterior é mais evidenciada entre os adolescentes. Das 18 crianças estudadas, apenas 5 preferem um destino turístico localizado fora do Brasil, mas oito dos 10 adolescentes preferem destinos fora do país. Já com relação ao ineditismo do local visitado, sete dos 10 adolescentes escolheram um destino onde nunca foram no exterior. As crianças citaram cidades como Rio de Janeiro, Porto Alegre, Curitiba. Já os adolescentes fazem descrições similares como as casas de parentes e são enfáticos em relação ao lugar e divulgam nomes de países: Canadá, Japão, Caribe, EUA e México.

Por último, as crianças e os adolescentes indicaram que pretendem visitar cidades e pontos turísticos ou locais turísticos. No geral as crianças e os adolescentes citaram apenas isso, sem discriminar qual ponto turístico seria esse. Isso demonstra que a criança e o adolescente já construíram a ideia de que cada cidade ou local terá alguns espaços específicos em que os turistas devem ir.

A partir das considerações efetuadas, construiu-se o Quadro 4. 
Quadro 4 - Resumo da categoria destino

\begin{tabular}{|c|c|c|c|}
\hline Categoria & Subcategoria & 10 a 11 anos & 14 anos \\
\hline \multirow{8}{*}{ Destino } & $\begin{array}{l}\text { Casa de } \\
\text { parentes }\end{array}$ & $\begin{array}{l}\text { Algumas crianças indicam que irão } \\
\text { viajar para a casa de parentes, como } \\
\text { madrinha e avós. }\end{array}$ & $\begin{array}{l}\text { Uma criança reportou que prefere } \\
\text { não viajar e ir para a casa do pai, } \\
\text { pois quase nunca tem tempo com } \\
\text { ele. }\end{array}$ \\
\hline & Hotéis & $\begin{array}{l}\text { As crianças relatam a vontade de } \\
\text { ir para hotéis de boa qualidade } \\
\text { (chique e maravilho) para aproveitar } \\
\text { as instalações do local (piscina, } \\
\text { chalé). }\end{array}$ & $\begin{array}{l}\text { Apenas um adolescente mencionou } \\
\text { a vontade de ir para um hotel de } \\
\text { frente para o mar. }\end{array}$ \\
\hline & Clube & $\begin{array}{l}\text { Apenas uma criança indicou querer } \\
\text { ir para um local que tem um clube } \\
\text { com piscina. }\end{array}$ & Não citado. \\
\hline & Cultura & Não citado. & $\begin{array}{l}\text { Diversos adolescentes indicam a } \\
\text { vontade de conhecer a cultura dos } \\
\text { lugares que irão visitar, apreender a } \\
\text { história, os costumes e a língua do } \\
\text { país. }\end{array}$ \\
\hline & Eventos & $\begin{array}{l}\text { Diversas crianças citaram que } \\
\text { gostariam de viajar para presenciar } \\
\text { um jogo de futebol do Corinthians. }\end{array}$ & Não citado. \\
\hline & Natureza & $\begin{array}{l}\text { Muitas crianças indicam quer passar } \\
\text { as férias em contato com a natureza, } \\
\text { principalmente na praia. Quase } \\
\text { nunca é citada a cidade onde estará } \\
\text { a praia, sendo essa vontade um } \\
\text { desejo mais genérico de estar numa } \\
\text { praia. }\end{array}$ & $\begin{array}{l}\text { Apenas um adolescente citou a praia } \\
\text { como local para a viagem, porém } \\
\text { grande parte das cidades citadas } \\
\text { estão situadas no litoral. }\end{array}$ \\
\hline & $\begin{array}{l}\text { Países e } \\
\text { cidades }\end{array}$ & $\begin{array}{l}\text { As cidades nacionais citadas foram: } \\
\text { Curitiba, Porto Alegre, Rio de } \\
\text { Janeiro. Os Estados nacionais citados } \\
\text { foram: Santa Catarina. } \\
\text { As cidades estrangeiras citadas } \\
\text { foram: Orlando, Cancun e Disney. } \\
\text { Os países citados foram: Estados } \\
\text { Unidos, Canadá e Caribe. }\end{array}$ & $\begin{array}{l}\text { A cidade nacional citada foi: } \\
\text { Divinópolis. } \\
\text { Estado nacional citado: Sergipe. } \\
\text { Cidades estrangeiras citadas: } \\
\text { Cancun, Orlando e Caribe. } \\
\text { Países citados: Suíça, Canadá, } \\
\text { México, Japão. }\end{array}$ \\
\hline & $\begin{array}{l}\text { Pontos } \\
\text { turísticos }\end{array}$ & $\begin{array}{l}\text { Algumas crianças citaram que } \\
\text { gostariam de conhecer pontos } \\
\text { turísticos e, de forma nominal, locais } \\
\text { no Rio de Janeiro. }\end{array}$ & $\begin{array}{l}\text { Os adolescentes indicaram que } \\
\text { gostariam de conhecer locais } \\
\text { turísticos importantes, conhecer } \\
\text { cidades e, em um caso, vulcões. }\end{array}$ \\
\hline
\end{tabular}

Fonte: Elaborado pelos autores.

Ao analisar as principais diferenças entre as crianças e os adolescentes, percebe-se que em ambos os casos existe uma compreensão de que o turismo pode ocorrer no Brasil e no exterior. Para os adolescentes cresce a importância ou o interesse de conhecer lugares fora do Brasil. Interessante notar que a 
grande maioria das citações de locais estrangeiros resume-se à América, com exceção de uma criança que gostaria de ir para o Japão, em função da origem japonesa da sua família e outra que gostaria de ir para a Suíça.

Além disso, identifica-se que as crianças valorizam de forma significativa lugares que possam ter o contato com a água. As menções à praia e à piscina são inúmeras. Os adolescentes não citam isso diretamente, porém escolhem locais onde a praia e a piscina estarão disponível.

\section{ATIVIDADES}

As principais atividades listadas pelos respondentes foram: socialização, recreação, show, mídia e informática, alimentação, natureza, esporte, relaxamento, compras e registro e lembrança.

As crianças e os adolescentes indicam de forma bastante clara a importância de atividades de socialização com familiares e amigos no decorrer da viagem. É interessante notar que, para as crianças, algumas atividades são relacionadas ao sexo feminino, como jogar vôlei, e outras ao sexo masculino, como jogar futebol e andar de kart. Adolescentes mencionam que esse processo de socialização com familiares envolve afeto, como, por exemplo, uma adolescente que informa que iria "abraçar família, beijar e não ia sair de perto deles".

As crianças e os adolescentes relatam diversas atividades que estão ligadas ao conceito de recreação. As crianças indicam que gostariam de jogar jogos de tabuleiro, empinar pipa, andar de carrinho de rolimã, fazer guerra d'água. Já os adolescentes indicam que querem ir a parques de diversão, andar de montanha russa, carrossel, elevador, pular de bungee jump.

Com relação a shows e festas, foram poucas as menções feitas para este tipo de atividade. Uma criança relatou que gostaria de ir a shows e uma adolescente reportou que gostaria de ir a festas.

As crianças demonstram que possuem uma grande predileção por atividades que envolvam computadores, jogos e videogames. Conforme destacam os estudos da Kaiser Family Foundation, esse comportamento é normal, pois as 
crianças estão cada vez mais expostas às influências da mídia e estão começando a consumir mais de uma mídia simultaneamente (RIDEOUT, 2007; ROBERTS et al., 1999; ROBERTS et al., 2005). Destaca-se que inúmeras crianças citaram videogames, mas apenas uma citou uma marca específica (Xbox360). Já os adolescentes não citaram nenhum item relacionado a esta subcategoria.

A alimentação foi citada inúmeras vezes como item importante nas viagens. As crianças indicam sua preferência por momentos de socialização em que irão comer picolé, comer fondue, marshmallow, dentre outras comidas que de certa forma indicam um momento de convivência com familiares ou amigos. Já os adolescentes citam que gostariam de frequentar lugares como Starbucks, restaurantes afrodisíacos, pizzarias, lanchonetes e comer comidas típicas e diferentes. Destaca-se um adolescente que informa que gostaria de fazer um piquenique. Algumas dessas atividades mencionadas parecem ter sido retiradas do imaginário ligado ao cinema, séries de televisão ou de outras fontes culturais.

A natureza aparece como outra subcategoria importante para as crianças e adolescentes. Mesmo que não tenham a compreensão direta que estão em busca de contato com a natureza, eles indicam que isso é importante. As crianças destacam a vontade de "curtir a vida ao ar livre, coisa que não faço há muito tempo", "olhar o pôr do sol", "aproveitar a paisagem" e "nadar com os golfinhos". Já os adolescentes querem ir para "praias que parecem surreais com sua beleza", "passar o dia todo na praia" e ir a um "lugar cheio de árvores".

Com relação aos esportes, as crianças citaram inúmeras vezes futebol e em menor número handebol e vôlei. Já os adolescentes não citaram nenhum esporte.

As crianças e os adolescentes indicam que estão necessitando de momento de relaxamento. Por exemplo, algumas crianças disseram que querem "curtir uma casa na praia com rede", "descansar", ter um "sossego de dar inveja". Já os adolescentes procuram um lugar para "relaxar e esquecer das responsabilidades", um "lugar calmo, tudo limpo, tudo certo, tranquilo de andar na rua" e uma oportunidade para "esquecer dos problemas". Percebe- 
se que a viagem começa a ter um significado de fuga da vida conturbada da cidade e das responsabilidades que vão se acumulando quando a criança passa para a adolescência.

A ideia de viajar para fazer compras está disseminada, tanto entre as crianças como adolescentes. Esta parece ser uma das atividades que mais tem apelo. As crianças demonstram que ir às compras pode ser uma diversão, pois lá é possível "Curtir nas lojas" e "comprar jogos e videogames muito legais". Já os adolescentes querem fazer compras, trazer lembranças e comprar coisas que talvez estejam fora do seu alcance econômico, como denota a seguinte reflexão de um adolescente: "as coisas que tenho vontade de comprar não são baratas, são muito caras". Além disso, os adolescentes também reconhecem que alguns produtos só estão disponíveis em outros países. Essa compreensão de que o sortimento de produtos oferecidos pelas lojas é diferente em outros países demonstra um conhecimento mais aprofundado das diferenças que existem.

Por último, algumas crianças e adolescentes demonstraram que têm uma necessidade de ter algum registro ou lembrança da viagem. Eles indicam que irão tirar muitas fotos para documentar o que aconteceu na viagem. Com o crescimento das mídias sociais nos últimos anos é natural que esse sentimento exista.

A partir das análises feitas, apresenta-se o Quadro 5, no qual são apresentadas as principais considerações com relação às atividades que as crianças e os adolescentes pretendem realizar. 


\begin{tabular}{|c|c|c|c|}
\hline Categoria & Subcategoria & 10 a 11 anos & 14 anos \\
\hline \multirow{10}{*}{ Atividades } & Socialização & $\begin{array}{l}\text { Muitas crianças revelam a vontade de } \\
\text { realizar atividades com membros da } \\
\text { família e, em menor proporção, com } \\
\text { amigos. Quando citam as atividades } \\
\text { desportivas, relacionam o esporte a } \\
\text { gênero ("futebol com pai e primos", } \\
\text { "vôlei com a mãe e madrinha"). }\end{array}$ & $\begin{array}{l}\text { Relatos mais afetivos e complexos } \\
\text { referentes à família ("abraçar", "beijar } \\
\text { e não sair de perto", "contar segredos", } \\
\text { "estarei ao lado do meu pai que quase } \\
\text { nunca eu vejo"). Alguns relacionam } \\
\text { amigos a diversão e o desejo de } \\
\text { conhecer novas pessoas e culturas. }\end{array}$ \\
\hline & Recreação & $\begin{array}{l}\text { Muitas crianças falam de brincadeiras } \\
\text { tradicionais ("jogos de tabuleiro", } \\
\text { "soltar pipa", "carrinho de rolimã") } \\
\text { e tipologias de parques: temático, } \\
\text { aquático, de diversão. Marca citada: } \\
\text { Beto Carrero World. }\end{array}$ & $\begin{array}{l}\text { Alusão a brinquedos mais elaborados } \\
\text { ou "radicais", como "montanha- } \\
\text { russa", "carrinho de bate-bate", } \\
\text { "bungee jump". Marca citada: Disney } \\
\text { (parques de Tóquio e Orlando). }\end{array}$ \\
\hline & Shows & $\begin{array}{l}\text { Uma criança citou artistas teens } \\
\text { como Jonas Brothers e Demi Lovato. }\end{array}$ & $\begin{array}{l}\text { Uma adolescente revelou a vontade } \\
\text { de "ir a muitas festas". }\end{array}$ \\
\hline & $\begin{array}{l}\text { Mídia e } \\
\text { informática }\end{array}$ & $\begin{array}{l}\text { As crianças citaram computador, TV } \\
\text { e, com maior incidência, videogame. } \\
\text { Uma delas falou do console Xbox } 360 \text {. }\end{array}$ & Nada foi citado. \\
\hline & Alimentação & $\begin{array}{l}\text { A maioria elenca doces ("picolé", } \\
\text { "chocolate"). Algumas atribuem a } \\
\text { hora da refeição com estar com } \\
\text { a família e citam genericamente } \\
\text { "comida boa", "gostosa". }\end{array}$ & $\begin{array}{l}\text { Algumas crianças relatam a vontade } \\
\text { de experimentar comidas diferentes } \\
\text { ou típicas. Marca citada: Starbucks. }\end{array}$ \\
\hline & Natureza & $\begin{array}{l}\text { Várias crianças afirmam que querem } \\
\text { aproveitar e curtir a natureza. } \\
\text { Atividades simples como "olhar o pôr } \\
\text { do sol" e "nadar pra caramba. }\end{array}$ & $\begin{array}{l}\text { Muitas crianças falam da vontade } \\
\text { de ir à praia. Caracterização mais } \\
\text { elaboradas como "surreais por sua } \\
\text { extrema beleza", "lugar frio que } \\
\text { neve", "animais marinhos". }\end{array}$ \\
\hline & Esporte & $\begin{array}{l}\text { São frequentemente citados } \\
\text { ("futebol", "vôlei, "handebol"). }\end{array}$ & Nada foi citado. \\
\hline & Relaxamento & $\begin{array}{l}\text { Algumas crianças revelam a vontade } \\
\text { de descanso e de "curtir uma praia } \\
\text { com rede". Uma delas cita "o sossego } \\
\text { de dar inveja", que denota uma } \\
\text { noção comparativa com o outro. }\end{array}$ & $\begin{array}{l}\text { As crianças apresentaram uma } \\
\text { preocupação em descansar, } \\
\text { mimetizando o discurso adulto como } \\
\text { "esquecer dos problemas" e "das } \\
\text { responsabilidades". Demonstram } \\
\text { vontade de ir a um lugar limpo, } \\
\text { bonito e seguro. }\end{array}$ \\
\hline & Compras & $\begin{array}{l}\text { O shopping é frequentemente } \\
\text { citado e ir às compras configura-se } \\
\text { como diversão com os pais. Marcas } \\
\text { desenhadas: O Boticário e Art Rock. }\end{array}$ & $\begin{array}{l}\text { Citam fazer compras, ir a shopping } \\
\text { e trazer lembranças. Demonstram } \\
\text { consciência que comprar não é } \\
\text { barato e que as lojas não estão } \\
\text { disponíveis em todos os lugares. } \\
\text { Marca citada: Apple. }\end{array}$ \\
\hline & $\begin{array}{l}\text { Registro e } \\
\text { lembrança }\end{array}$ & $\begin{array}{l}\text { Algumas crianças demonstram a } \\
\text { vontade em tirar fotos para registrar } \\
\text { os momentos. }\end{array}$ & $\begin{array}{l}\text { Uma criança relata que "quer trazer } \\
\text { muitas fotos", enquanto outra } \\
\text { acrescenta que quer ser fotógrafa } \\
\text { para treinar na profissão. }\end{array}$ \\
\hline
\end{tabular}

Fonte: Elaborado pelos autores. 
Ambos os grupos escreveram que "seria muito legal", "muito divertido", "os dias serão legais" e "um lugar encantador", demonstrando alegria e felicidade. A viagem atrelada a tais emoções fornecem um caráter hedônico e refletem a necessidade pelo prazer, diversão e excitação (BIGNÉ; MATTILA; ANDREU, 2008).

A diferença observada é que as crianças mais novas relacionam essa experiência agradável à presença e à interação com pais e demais familiares: "curtir a vida com quem você ama" "se divertir com família e amigos". As mais velhas (14 anos), por sua vez, atrelam a diversão e a alegria à vontade de sentir algo novo ("uma realidade diferente da minha") e associam "medo e insegurança" a uma conotação positiva de descoberta. Isto está voltado à inter-relação entre afeto e cognição e é semelhante ao efeito "hands-on, mind on, heart on", no qual a descoberta e a ação (ou engajamento motor, cognitivo e emocional) influenciam a atitude acerca do serviço (CSIKSZENTMIHALYI; HERMANSON, 1995).

As crianças que estão no estágio refletivo (11 a 16 anos), representadas pelo grupo de 14 anos, demonstram conhecimento de mercado mais elaborado e complexo à medida que desenvolvem o processamento de informações e suas habilidades sociais. Ao chegar à adolescência, tornam-se mais focadas em significados e em peculiaridades relativos ao ato de consumir (JOHN, 1999). Muitas delas atribuíram "sonho de consumo" e "maior sonho" à viagem, além de uma unicidade ao momento ("será o nosso momento", "aproveitar até o último segundo").

Esses mesmos adolescentes já possuem uma noção mais apurada da influência da propaganda na sua forma de pensar e sentir (afetando desejos e necessidades), o que transcende o mero caráter informativo da mídia observado pelas crianças mais novas (10 a 11 anos): "quando eu vi essa propaganda, eu fiquei ansioso. [...] eu queria ir logo pra esse parque" e "crio a esperança de ver esse lugar". Há uma forte influência da propaganda quando esta provém informações sobre consumo e valor de bens e serviços (GORN; FLORSHEIM 1985; MARTIN; GENTRY 1997). Isso corrobora com os achados de Bjurstrom (1994) e Elding (1999) quando afirmam que é aos 12 anos, ou cerca disso, que se pode ter mais certeza de que a criança desenvolveu um entendimento integral 
do propósito da propaganda e da sua influência. McNeal (1999) afirma também que, apesar do crescente desgosto à propaganda com a chegada da maturidade, as crianças admitem que são influenciadas no seu comportamento de compra. $O$ resumo na análise da categoria pode ser consultado no Quadro 6.

\begin{tabular}{|c|c|c|c|}
\hline Categoria & Subcategoria & 10 a 11 anos & 14 anos \\
\hline \multirow{4}{*}{ Emoções } & Novidade & $\begin{array}{l}\text { Uma criança fala que a mãe queria } \\
\text { algo novo. Em geral, optam por } \\
\text { algo aconchegante ou até ser bem } \\
\text { recebida pela família (não buscam } \\
\text { tantas novidades). }\end{array}$ & $\begin{array}{l}\text { Algumas crianças falam da vontade } \\
\text { de sentir o novo ou uma "realidade } \\
\text { diferente da minha", verbalizam } \\
\text { ainda "medo e insegurança" com } \\
\text { conotação de descoberta. }\end{array}$ \\
\hline & $\begin{array}{l}\text { Felicidade/ } \\
\text { Alegria }\end{array}$ & $\begin{array}{l}\text { Relacionam a alegria e a diversão a } \\
\text { estar com a família e amigos (ou a } \\
\text { revê-los devido à saudade e à falta } \\
\text { de tempo). }\end{array}$ & $\begin{array}{l}\text { Viagem de férias como momento } \\
\text { único ("será o nosso momento") e } \\
\text { da esperança em viajar. }\end{array}$ \\
\hline & $\begin{array}{l}\text { Sonho } \\
\text { (idealização) }\end{array}$ & $\begin{array}{l}\text { Apenas uma criança relata o desejo } \\
\text { de "correr atrás de um sonho". }\end{array}$ & $\begin{array}{l}\text { Muitas falam da vontade de realizar } \\
\text { um "sonho de consumo". Algumas } \\
\text { demonstrações de resignação pois o } \\
\text { sonho "terá que esperar". }\end{array}$ \\
\hline & Ansiedade & $\begin{array}{l}\text { Algumas crianças falam em } \\
\text { "aproveitar cada momento", "curtir a } \\
\text { vida" e que "morre de vontade". }\end{array}$ & $\begin{array}{l}\text { Algumas crianças falam da } \\
\text { agitação e da ansiedade gerada } \\
\text { pela propaganda. Outras falam em } \\
\text { "aproveitar até o último segundo". }\end{array}$ \\
\hline
\end{tabular}

Fonte: Elaborado pelos autores.

Além das semelhanças e das diferenças evidenciadas, há uma conexão da felicidade da criança associada à dos pais e esta é assimilada pela criança quando diz que é "meu maior sonho, só iria sorrir, e também o sonho da minha mãe, pois se eu estou feliz ela também fica feliz" (14 anos). Tal afirmação mostra a consciência do filho sobre sua importância para os pais e, com essa compreensão, facilita o próprio processo de influência e persuasão por parte da criança que se percebe como protagonista na vida familiar.

Noções quanto à efemeridade da infância da adolescência e de tradeoffs, incluindo transações financeiras, também se destacaram no discurso dos adolescentes: "gosto de aproveitar bastante para aproveitar meu tempo de adolescente" e "viajar não é barato". Trata-se de um discurso que evidencia o 
amadurecimento das crianças pela percepção da passagem do tempo e pela própria escassez de recursos.

\section{CONSIDERAÇÕES FINAIS}

A questão da influência da criança sobre as compras da família é um ponto debatido constantemente entre os profissionais e o marketing. O objetivo deste trabalho foi identificar os atributos valorizados por crianças e adolescentes na escolha de destinos turísticos. Para atingir esse objetivo foram coletados desenhos e material escrito de crianças e adolescentes (PALAN; WILKES, 1997). Esse material foi analisado por meio da técnica de análise de conteúdo e os principais resultados estão listados a seguir.

A influência exercida por crianças varia por categoria de produto. Para alguns produtos, eles são iniciadores ativos, pessoas que buscam informações e compradores; enquanto que para outras categorias de produtos, eles influenciam as compras feitas pelos pais. $\mathrm{O}$ ato de comprar é regido pela forma como foram socializadas para agir como consumidores. Familiares, colegas e mídia são fundamentais agentes de socialização para as crianças no jogo comunicação (KAUR; SINGH, 2006).

A principal fonte de motivação para viajar é a família. Seja para visitar parentes, ou como prêmio para bom comportamento ou para um aniversário, a viagem funciona como um momento em que a criança irá conviver de forma mais próxima com seus familiares. Já para os adolescentes, a principal motivação para viajar são os amigos (MOSCHIS; CHURCHILL, 1978). Diante desses resultados, as agências de turismo podem direcionar sua comunicação para salientar os apelos que esse grupo considera mais importante. Propagandas voltadas para as famílias com crianças provavelmente terão maior efetividade ao apresentar a criança realizando atividade com os pais, já propagandas direcionadas para adultos podem utilizar cenários ou cenas em que o adolescente está sozinho com outros adolescentes. Como se trata de uma fase de transição, talvez não seja tão interessante colocar somente adolescentes na propaganda.

A forma como as crianças e os adolescentes irão chegar ao local turístico não foi citada de forma significativa pelos respondentes. Isso aconteceu porque 
eles não foram alvo de questões especificas sobre o meio de transporte no momento da coleta de dados.

As pessoas que farão parte da viagem são basicamente a família, incluindo pais, tios, padrinhos, primos e irmãos. Porém cabe destacar que, para os adolescentes, começa a crescer a importância dos amigos. A impossibilidade de viajar sozinho ainda limita o impacto dessa vontade, porém é algo que o adolescente valoriza. A ideia de que ele poderá conviver com outros adolescentes e não ficará o tempo todo com seus pais terá muito apelo.

Com relação aos destinos preferidos, identificou-se que, para crianças, o apelo da água é muito grande. Elas querem ir para locais onde possam estar na piscina ou na praia. Essas crianças se dividem entre aquelas que querem conhecer o Brasil e aquelas que querem conhecer outros países. Os adolescentes não valorizam de forma direta a praia e a piscina, porém em muitas ocasiões indicam querer ir para cidades litorâneas. Tanto as crianças como adolescentes estão focados em locais turísticos da América, citando apenas um país da Ásia e um país da Europa. Destaca-se que os adolescentes já começam a querer conhecer outras culturas, experimentando o idioma, a culinária e conhecendo os costumes. Essas informações indicam de que forma devem ser apresentadas as informações de um pacote de viagens para famílias. Para crianças, seria importante destacar a infraestrutura do hotel, apresentando a piscina ou a proximidade com a praia. Já para adolescentes seria interessante destacar a possibilidade de conhecer outra cultura e ter momentos de convivência com outros adolescentes.

As atividades que as crianças e os adolescentes pretendem realizar na viagem envolvem basicamente uma série de oportunidades de interação com amigos e familiares e visitas a locais onde podem ser realizadas diversas atividades. As crianças estão mais focadas em participar de atividades mais tradicionais, enquanto os adolescentes focam mais em atividades que envolvam algum tipo de emoção. Por isso os parques de diversão são atrativos para esses grupos, pois possibilitam realizar atividades com outras crianças e vivenciar emoções em diversos brinquedos. Além disso, as crianças demonstram desejar que exista alguma infraestrutura com acesso a videogames e jogos (RIDEOUT, 2007; ROBERTS et al., 1999; ROBERTS et al., 2005). Os adolescentes vão querer 
algo mais ativo, como pular de bungee jump. Destaca-se que as crianças e os adolescentes começam a exibir comportamentos que antes eram mais comuns em adultos. Eles indicam que precisam de um momento de relaxamento para descansar e fugir das responsabilidades do dia a dia. Essa necessidade pode explicar a importância que o contato com a natureza assume para o público pesquisado. Tanto as crianças como os adolescentes reportaram que gostariam de ver o pôr do sol, aproveitar a paisagem, curtir uma rede e descansar.

A questão da alimentação surgiu na pesquisa como fonte de diversão para as crianças e adolescentes. Eles relatam os locais onde gostariam de comer, o tipo de comida e a vontade de provar comidas diferentes. Outra atividade que teve bastante importância para as crianças foram as compras, pois eles já compreendem que os ambientes de compra são atrativos e divertidos. Os adolescentes já têm uma visão mais elaborada do processo de consumo e compreendem que em outros países existem produtos que não estão disponíveis no Brasil. É lá que eles gostariam de fazer compras.

A alegria em viajar foi presenciada em ambos os grupos. As crianças atribuíam a estar com os pais, enquanto os adolescentes ressaltaram a questão da novidade e da descoberta. Os destinos turísticos, principalmente para os mais velhos, são associados à idealização de um sonho de consumo (JOHN, 1999). A ansiedade em viajar e aproveitar o momento são elementos perceptíveis nos discursos das crianças (BIGNÉ; MATTILA; ANDREU, 2008), mas, de uma forma mais profunda, os mais velhos já vislumbram o fim de um estágio (infância e adolescência) e uma noção maior acerca da limitação de recursos financeiros.

A ausência do pesquisador no momento da coleta de dados, apesar da comunicação direta com a professora; a amostra ser coletada em uma única escola (limitada ao estudo de 28 estudantes); assim como a utilização de técnicas diferentes para as duas amostras de crianças e adolescentes configuram-se como limitações do estudo.

Sugere-se, para pesquisas futuras sobre o tema, a análise da influência de crianças em estágio perceptual (3 a 7 anos), atentando para suas peculiaridades e metodologia adequada. Pode-se, também, empreender estudos relativos a coalizões familiares (pai e filho, irmãos, mãe e filha, por exemplo) e o seu reflexo 
na decisão de compra de produtos turísticos. Sugerem-se, ainda, estudos quantitativos que avaliem atributos na escolha de crianças e adolescentes por determinado produto ou serviço. A idade das crianças e dos adolescentes pode ser ampliada em futuras pesquisas.

\section{REFEÊNCIAS}

AHUJA, R. B.; STINSON, K. M. Female-headed single parent families: An exploratory study of children's influence in family. Advances in consumer research, v. 20, n. 1, p. 469-474, 1993.

BARDIN, L. Análise de conteúdo. Edições 70 - Brasil, 2012.

BARRY, T. E. A framework for ascertaining deception in children's advertising. Journal of Advertising, v. 9, n. 1, p. 11-18, 1980.

BELCH, G. E.; BELCH, Michael A.; CERESINO, Gayle. Parental and teenage child influences in family decision making. Journal of business research, v. 13, n. 2, p. 163-176, 1985.

BEREY, L. A.; POLLAY, Richard W. The influencing role of the child in family decision making. Journal of Marketing Research, p. 70-72, 1968.

BEULKE, C. S.; GIB, S. A influência do consumidor infantil sobre os pais na tomada de decisão de compra de produtos alimentícios. In: Anais do XXVIII Congresso Brasileiro de Ciências da Comunicação-Intercom. UERJ, Rio de Janeiro, Brasil. 2005.

BIGNÉ, J. E.; MATTILA, A. S.; ANDREU, L. The impact of experiential consumption cognitions and emotions on behavioral intentions. Journal of Services Marketing, v. 22, n. 4, p. 303315, 2008.

BLICHFELDT, B. S. et al. Tweens Tourists: Children and Decision-Making. Journal of Tourism Consumption and Practice, v. 2, n. 1, p. 1-24, 2010.

BJURSTRÖM, Erling. Children and television advertising: A critical study of international research concerning the effects of TV-commercials on children. 1994.

BURNS, A. C.; HARRISON, M. C. Children's self-perceptions of their participation in retail store patronage decisions. Developments in Marketing Science, v. 5, p. 66-69, 1982.

CAMPOMAR, M. C. Do uso de "estudo de caso" em pesquisas para dissertações e teses em administração. Revista de Administração, São Paulo, v. 26, n. 3, p. 95-97, 1991. 
CHIZZOTTI, A. Pesquisa em ciências humanas e sociais. Cortez, 1991.

CONNELL, J. Toddlers, tourism and Tobermory: Destination marketing issues and televisioninduced tourism. Tourism Management, v. 26, n. 5, p. 763-776, 2005.

CONVERSE, P. D.; CRAWFORD, C. M. Family buying: who does it? Who influences it? Current Economic Comment, v. 11, p. 28-50, 1949.

CSIKSZENTMIHALYI, M.; HERMANSON, K. (1995), "Intrinsic motivation in museums: what makes visitors want to learn? Museum News, Vol. 74 No. 3, pp. 34-37, 1995.

CULLINGFORD, C. Children's attitudes to holidays overseas. Tourism Management, v. 16, n. 2, p. 121-127, 1995.

DARLEY, W. F.; LIM, J. Family decision making in leisure-time activities: An exploratory investigation of the impact of locus of control, child age influence factor and parental type on perceived child influence. Advances in consumer research, v. 13, n. 1, p. 370-374, 1986.

DAVIS, H. L. Decision making within the household. Journal of consumer research, p. 241260, 1976.

DUNNE, M. The role and influence of children in family holiday decision making. International Journal of Advertising and Marketing to Children, v. 1, n. 3, p. 181-191, 1999.

EKSTROM, K. M.; TANSUHAJ, P. S.; FOXMAN, Ellen R. Children's influence in family decisions and consumer socialization: a reciprocal view. Advances in consumer research, v. 14, n. 1 , 1987.

ENGEL, J. F.; BLACKWELL, R. D.; MINIARD, P. W. Comportamento do Consumidor. 8. ed. Rio de Janeiro: LTC, 2000.

FILIATRAULT, P.; RITCHIE, JR B. Joint purchasing decisions: A comparison of influence structure in family and couple decision-making units. Journal of Consumer Research, p. 131-140, 1980.

FLICK, U. Desenho da pesquisa qualitativa: Coleção Pesquisa qualitativa. Bookman, 2009.

FODNESS, D. The impact of family life cycle on the vacation decision-making process. Journal of travel research, v. 31, n. 2, p. 8-13, 1992.

FOXMAN, E. R.; TANSUHAJ, P. S. Adolescents' and mothers' perceptions of relative influence in family purchase decisions: patterns of agreement and disagreement. Advances in consumer research, v. 15, n. 1, p. 449-453, 1988. 
FOXMAN, E. R.; TANSUHAJ, P. S.; EKSTROM, K. M. Family members' perceptions of adolescents' influence in family decision making. Journal of Consumer Research, p. 482-491, 1989.

GAMRADT, J. Jamaican children's representations of tourism. Annals of Tourism Research, v. 22 n. 4 p.735-762, 1995.

GEUENS, M.; MAST, G.; DE PELSMACKER, P. Children's influence on family purchase behavior: the role of family structure. In: Asia Pacific Advances in Consumer Research Conference. Association for Consumer Research, 2002. p. 130-135.

GRAM, M. Family holidays. A qualitative analysis of family holiday experiences. Scandinavian Journal of Hospitality and Tourism, v. 5, n. 1, p. 2-22, 2005.

GORN, G. J.; FLORSHEIM, R. The effects of commercials for adult products on children. Journal of Consumer Research, p. 962-967, 1985.

HALAN, D. Why kids mean business. Indian Management, v. 41, n. 12, p. 46-9, 2002.

HALL, J. et al. Influence of children on family consumer decision making. European Advances in Consumer Research, v. 2, p. 45-53, 1995.

HEMPEL, D. J. Family buying decisions: A cross-cultural perspective. Journal of Marketing Research, p. 295-302, 1974.

HOLDERT, F.; ANTONIDES, G. Family Type Effects on Household Members' Decision Making. Advances in consumer research, v. 24, n. 1, 1997.

HOWARD, D. R. et al. Who makes the decision: the parent or the child? The perceived influence of parents and children on the purchase of recreation services. Journal of Leisure Research, v. 22, n. 3, p. 244-258, 1990.

IBGE - Instituto Brasileiro de Geografia e Estatística. Censo de 2010. Disponível em: www. ibge.gov.br. Acesso em: 30/01/2014.

JENKINS, R. L. The influence of children in family decision-making: parents' perceptions. Advances in consumer research, v. 6, n. 1, p. 413-418, 1979.

JENSEN, J. M. Children's purchase requests and parental responses: results from an exploratory study in Denmark. European Advances in Consumer Research, v. 2, n. 1, p. 54-60, 1995.

JOHN, D. R. Consumer socialization of children: A retrospective look at twenty-five years of research. Journal of consumer research, v. 26, n. 3, p. 183-213, 1999.

KRIPPENDORFF, K. Content Analysis: An Introduction to Its Methodology. [Los Angeles]: Sage Publications, 2013. 
MANGLEBURG, T. F.; TECH, V. Children's influence in purchase decisions: a review and critique. Advances in Consumer Research, v. 17, n. 1, p. 813-825, 1990.

MANGLEBURG, T. F.; GREWAL, D; BRISTOL, T. Family type, family authority relations, and adolescents' purchase influence. Advances in Consumer Research, v. 26, p. 379-384, 1999.

MARTIN, M. C.; GENTRY, J. W. Stuck in the model trap: The effects of beautiful models in ads on female pre-adolescents and adolescents. Journal of Advertising, v. 26, n. 2, p. 19-33, 1997.

MCNEAL, J. U. Kids as customers: a handbook of marketing to children. Nova York: Lexinton Books, 1992.

MCNEAL, J. U. On becoming a consumer. Woburn, MA: Butterworth-Heinemann, 2007.

MCNEAL, J. U. The kids market: myths and realities. Nova York: Paramount Books, 1999. $272 p$.

MCNEAL, J. U.; YEH, Chyon-Hwa. Development of consumer behavior patterns among Chinese children. Journal of Consumer Marketing, v. 14, n. 1, p. 45-59, 1997.

MEHROTRA, S.; TORGES, S. Determinants of children's influence on mothers'buying behavior. Advances in Consumer Research, v. 4, n. 1, 1977.

MICHAELIS. Dicionário Prático de Língua Portuguesa. São Paulo: Melhoramentos. 2014.

MINISTÉRIO DO TURISMO - Ministério do Turismo, disponível em <www.mtur.gov.br>, acessado em 30 jan. 2014.

MONTIGNeAUX, N. Público alvo: crianças, a força dos personagens e do marketing para falar com o consumidor infantil. Rio de Janeiro: Campus, 2003.

MOSCHIS, G. P.; CHURCHILL JR, G. A. Consumer socialization: A theoretical and empirical analysis. Journal of Marketing Research, p. 599-609, 1978.

MOSCHIS, G. P.; MITCHELL, L. G. Television advertising and interpersonal influences on teenagers' participation in family consumer decisions. Advances in consumer research. v. 13, n. 1, p. 181-186, 1986.

MOZZATO, A. R.; GRZYBOVSKI, D. Análise de conteúdo como técnica de análise de dados qualitativos no campo da administração: potencial e desafios. Revista de Administração Contemporânea, v. 15, n. 4, p. 731-747, 2011. 
NICKERSON, N. P.; JUROWSKI, C. The influence of children on vacation travel patterns. Journal of Vacation Marketing, v. 7, n. 1, p. 19-30, 2001.

NOVALO, N. Y. A influência da criança no processo decisório da família. Iniciação Científica. (Graduação em Administração) - PiBic CNPQ / FEA-USP. Orientação de Andrés Rodriguez Veloso. São Paulo: USP, 2012.

NOVALO, N. Y.; VELOSO, A.R. A Influência da criança no processo decisório da família. Simpósio de internacional de iniciação científica da Universidade de São Paulo, 2012.

OCKE, M. A. O Processo de Decisão de Compra de Férias da Família. Turismo em Análise, v. 24, n०. 3. 2013.

MARSHALL, C.; ROSSMAN, G. B. Data collection methods. Designing qualitative research, v. 2, 1995.

RIDEOUT, V. J. Parents, Children \& Media - A Kaiser Family Foundation Survey. June 2007, p. 1-42.

ROBERTS, D. F.; FOEHR, U. G.; RIDEOUT, V. J.; BRODIE, M. Kids \& Media @ The New Millenium. Kaiser Family Foundation Report, Nov., 1-89.

ROBERTS, D. F.; FOEHR, U. G.; RIDEOUT, V. J. Generation M: Media in the Lives of 8-18 YearsOld - A Kaiser Family Foundation Study. March, 2005, p. 1-145.

RUST, L. Observations: Parents and Children Shopping Together. Journal of Advertising Research, v. 33, p. 65-70, 1993.

RYAN, C. The child as a visitor. World Travel and Tourism Review, v. 2, p. 135-139, 1992.

SHARP, H.; MOTT, P. Consumer decisions in the metropolitan family. The Journal of Marketing, p. 149-156, 1956.

SINGH, D. Children as consumers. Indian Management, v. 37, n. 9, p. 78-81, 1998.

SCHOR, J. Born to buy: The commercialized child and the new consumer culture. Simon and Schuster, 2004.

SEATON, A. V. et al. Disaggregating friends and relatives in VFR tourism research: the Northern Ireland evidence 1991-1993. Journal of Tourism Studies, v. 6, n. 1, p. 6-18, 1995.

SMITH, C. P. Content analysis and narrative analysis in REIS, Harry T.; JUDD, Charles M. (Ed.). Handbook of research methods in social and personality psychology. Cambridge University Press, p. 313-335, 2000. 
STEMPEL, G.H. Content analysis. In: STEMPEL, G. H.; WESTLEY, B. H. (Ed.). Research methods in mass communications, Englewood Cliffs NJ: Prentice-Hall, 1989.

SZYBILLO, G. J.; SOSANIE, A. Family decision making: husband, wife and children. Advances in consumer research, v. 4, n. 1, p. 46-49, 1977.

THOMSON, E. S.; LAING, A. W.; MCKEE, L. Family purchase decision making: Exploring child influence behaviour. Journal of Consumer Behaviour, v. 6, n. 4, p. 182-202, 2007.

THORNTON, P. R.; SHAW, G.; WILLIAMS, A. M. Tourist group holiday decision-making and behaviour: the influence of children. Tourism Management, v. 18, n. 5, p. 287-297, 1997.

VECCHIO, G. Creating Ever-Cool: A Guide to a Kids Heart. Louisiana: Pelican Publishing, 2002.

VELOSO, A. R.; HILDEBRAND, D. F. N.; CAMPOMAR, M. C. Children Influences and Family Decision Making. In: 2010 BALAS Annual Conference, 2010.

VELOSO, A. R.; HILDEBRAND, D.; CAMPOMAR, M. C. Marketing e o Mercado Infantil. São Paulo: Cengage Learning, 2012.

VELOSO, A. R.; HILDEBRAND, D. F. N.; ALBUQUERQUE, C. A. Coleta de desenhos com crianças como ferramenta de pesquisa de marketing. In: Semead - Seminários em Administração FEA/USP, 2013, São Paulo. Anais do XVI SEMEAD Seminários em Administração FEAUSP, 2013.

WILLIAMS, L. A.; VEECK, A. An exploratory study of children's purchase influence in urban China. Asia Pacific Advances in Consumer Research, v. 3, p. 13-19, 1998. 